\title{
Herencia de los exempla jesuitas. Homenaje a la obra de Danièle Dehouve
}

\author{
Dominique Raby
}

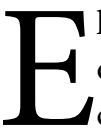
15 de octubre de 2011 se presentó en la unidad Distrito Federal del Centro de Investigaciones y Estudios Superiores en Antropología Social (CIESAs) el libro de Danièle Dehouve Relatos de pecados en la evangelización de los indios de México (siglos XVI-XVIII), traducido por Josefina Anaya y publicado en 2010 por esta misma casa de estudios en su colección Publicaciones de la Casa Chata. Tuve el honor de participar en el evento con la autora y con David Robichaux (Universidad Iberoamericana), Solange Alberro (El Colegio de México) y Virginia García Acosta (directora general del CIESAS). En esa ocasión presenté a manera de homenaje un estudio breve de un relato nahua contemporáneo, elaborado a partir de las características de los ejemplos - también llamados exempla o relatos de pecados- jesuitas, tan finamente analizadas en la obra. El presente texto es una versión modificada $y$ ampliada de ese homenaje.

Mi propósito entonces no es presentar el impresionante libro de Dehouve, el cual da a conocer, contextualiza y analiza una muestra de 44 exempla y una pequeña obra de teatro, traducidos o reescritos en náhuatl por los jesuitas, a partir del texto en náhuatl con traducciones originales al español y al francés. Dejaré de lado varios aspectos sumamente interesantes de esta obra para ofrecer al lector una muestra del potencial del análisis de la autora y lograr una mejor comprensión de la literatura nahua contemporánea y de su riqueza a partir de un relato moderno. No pretendo demostrar la sobrevivencia de un ejemplo jesuita determinado en el relato, sino señalar la herencia de los relatos de pecados jesuitas en la tradición oral nahua, a través de algunos aspectos morfológicos, lingüísticos y de contenido presentes en las dos tradiciones. Así, puede subrayarse el dinamismo y la heteroglosia de la tradición oral, la cual integra, transforma, reinterpreta y amalgama elementos de diversa índole, entre los que el relato de pecado jesuita sólo es uno, pero poco estudiado hasta ahora desde esta perspectiva. Esta falta de estudios se explica de manera sencilla: la obra de Danièle Dehouve es la primera en hacer disponibles los exempla jesuitas en náhuatl y su análisis.

\section{Heritage of the Jesuit Exempla. Essay in Homage to Danièle Dehouve's Work}


Antes de la publicación de su libro no existía la posibilidad de reconocer con precisión las características de estos relatos en la tradición oral contemporánea.

\section{LOS EXEMPLA EN NÁHUATL DE LOS JESUITAS}

Los exempla pueden definirse como breves anécdotas usadas principalmente en sermones para convencer a los feligreses. Estos relatos, nos informa el capítulo 1, aparecen entre los siglos IV y viII, y uno de sus autores más antiguos es San Agustín. Pero la "edad de oro" de los exempla empieza en el siglo XIII, cuando las anécdotas morales son reunidas en recopilaciones o incluidas en sermonarios. Después de un agotamiento de la producción a mediados del siglo XIV, se observa a partir del siglo XVI —con el Concilio de Trento- un renacimiento de la predicación y de los exempla. En efecto, la Iglesia católica debe entonces luchar en tres frentes: combatir la recién "descubiertas" en Asia y América y recristianizar a las poblaciones rurales de Europa. Los jesuitas, cuya orden mejor encarna el espíritu de la Contrarreforma, son los principales actores de este renacimiento de la literatura ejemplar.

Desde su llegada en 1572 hasta su expulsión en 1770, los misioneros jesuitas en Nueva España, objeto del capítulo 2, fueron los principales difusores de exempla. Se dedicaron a traducir las anécdotas en náhuatl, las llamaron neixcuitilli o ixcuitilli - ejemplo-. Además recopilaron nuevas anécdotas edificantes en sus misiones alrededor del mundo, las cuales transformaron y reunieron en compilaciones que, a su vez, fueron distribuidas en Europa, Asia y América. Las prédicas en lenguas indígenas de los jesuitas eran famosas y, según los misioneros, exitosas. Marcadas por una "pedagogía del temor” (p. 69), insistían en los tormentos infernales. Los relatos de pecados, de acuerdo con los principios elaborados por el fundador de la orden jesuita, Ignacio de Loyola, usaban vívidas imágenes que involucraban

los cinco sentidos. Se acompañaban en ocasión de fiestas religiosas de pequeñas obras de teatro en el mismo estilo.

Los siguientes capítulos de la obra exponen cómo los jesuitas procedieron a un amplio trabajo de deconstrucción y reconstrucción de la lengua y del universo mental nahua. Así, la historia de los relatos ejemplares es una sucesión de transformaciones y de malentendidos interculturales orquestados por los jesuitas con el fin de reducir las experiencias de los nativos al molde del "pecador universal", hombre ficticio conforme al modelo europeo, castigado de manera estereotipada. El capítulo 11 invierte la mirada: ¿cuáles fueron las transformaciones y los malentendidos del lado de la otra cultura, la recipiente, es decir la náhuatl? ¿Cómo se apropiaron estas imágenes? ¿Cómo los relatos pasaron de una lógica eclesiástica a otra más pueblerina? El proceso durante la Colonia no dejó huellas, pero la tradición oral actual de los pueblos indígenas de México manifiesta numerosas convergencias con los exempla jesuitas. El capítulo reúne una muestra de la herencia de los relatos de pecados no sólo en los denominados "cuentos", sino también en rumores y otras expresiones de la oralidad.

\section{UN EJEMPLO MODERNO: EL VIAJE AL MUNDO DE LOS MUERTOS}

En las páginas que siguen desarrollaré con más detalle ejemplos de esta herencia en un relato nahua de la región del Alto Balsas en el estado de Guerrero. Este relato me fue contado en náhuatl por varios narradores, hombres y mujeres, entre 2002 y 2006, y los grabé en el marco de un proyecto sobre el discurso femenino en la tradición oral. ${ }^{1}$ Estas narraciones dejan ver variaciones importantes unas respecto de otras que estudié en otro ensayo, pero aquí me

\footnotetext{
${ }^{1}$ Las grabaciones fueron depositadas en el sitio del Archivo de los Idiomas Indígenas de Latinoamérica de la University of Texas, en línea: <http://www.ailla.utexas.org/site/welcome_sp.html>.
} 


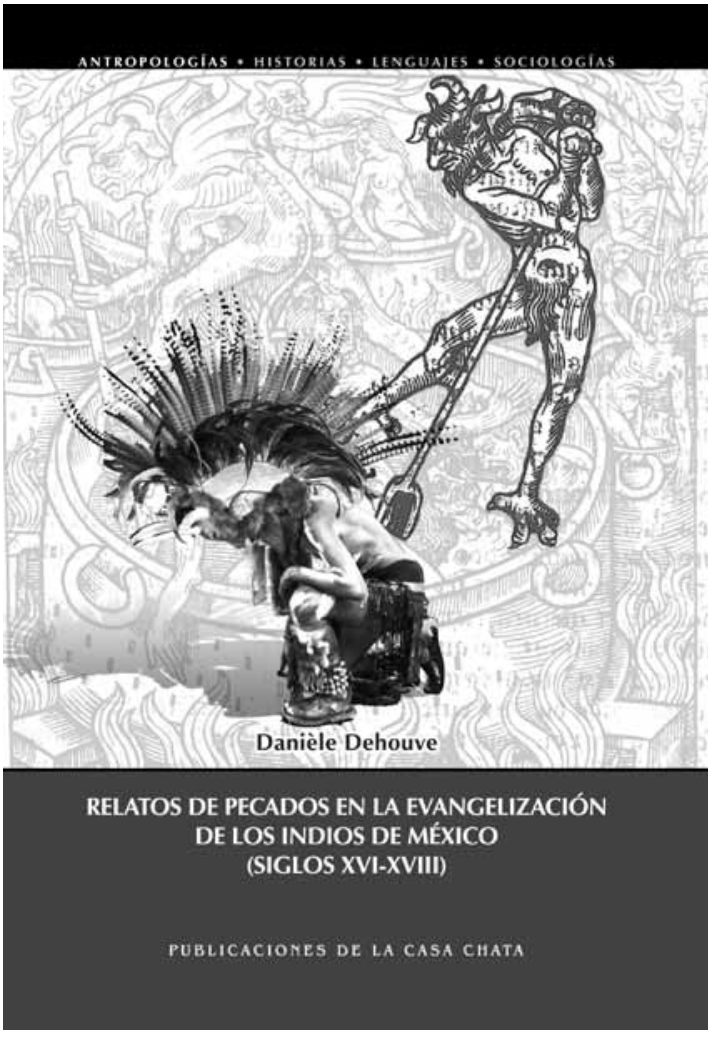

interesa destacar el guión común. Se desarrolla así: un hombre va a trabajar fuera del pueblo, momento durante el cual su esposa toma un amante y muere. El hombre regresa a su pueblo y, desesperado, busca a su esposa hasta el mundo de los muertos gracias a la ayuda de un buitre cabecirroja. Una vez allá, el hombre observa la vida cotidiana de su esposa - en unas versiones es castigada por diablos, en otras vive feliz con amantes-y luego regresa a la tierra con el buitre. Algunos de los narradores nahuas consideran este relato como un "ejemplo", también llamado en náhuatl ixkuitilli. Este último término es usado hoy en la comunidad para designar un relato, una imagen, una representación con actores o una experiencia que enseña o hace creer en algo.

A pesar de su tema, parecido al Orfeo de la Antigüedad europea, el relato del viaje al mundo de los muertos es reconocido como de origen indígena en la literatura antropológica, puesto que se encuentra desde el norte de Canadá hasta Venezuela - en variantes acordes a cada cultura- y dejó huellas en los mitos, sortilegios y cantos rituales del México prehispánico (Soustelle, 1956; Raby, 2003). El relato del Alto Balsas incluye numerosos elementos de la cosmología nahua de origen prehispánico que no analizaré aquí: el mundo de los muertos - Chiknaujtipan - como espejo de la vida terrestre, con casas, iglesia, ríos, jardines, objetos cotidianos y relaciones sociales; el buitre como espíritu ligado a la muerte; las ofrendas al muerto, etc. Otros elementos, sin embargo, están presentes en las dos tradiciones - la nahua prehispánica y la cristiana - y probablemente tienen su origen en los exempla jesuitas, lo que demuestra una vez más la riqueza y complejidad del sincretismo en México. Los analizaré aquí alrededor de tres ejes principales: la estructura del relato, la concepción del pecado y la visión del infierno o mundo de los muertos.

\section{MUERTE SÚBITA Y CONCEPCIÓN DE LOS PECADOS}

En el capítulo 3 de su obra, Danièle Dehouve identifica, inspirada en las "funciones" de Vladimir Propp, tres principales tipos de exempla: "pecado-muerte-visión del castigo sobrenatural", "puesta a pruebaarrepentimiento (o liberación)" y "pecado-muerte castigo". Las dos primeras estructuras son de origen medieval, pero la tercera es principalmente moderna y muy apreciada en la España del siglo xvir. En Nueva España en particular los misioneros tenían predilección por espantar a sus fieles indígenas con relatos de este tipo, en los que la muerte súbita es la consecuencia directa del pecado. El relato moderno que analizo aquí fusiona dos tipos: las series "pecadomuerte súbita como castigo" y "pecado-muerte-visión del castigo por un tercero". Empezaré por el primero, en el que la esposa muere súbitamente por haber sido adúltera: es tan evidente que el relato no precisa la razón de su fallecimiento, aunque es 
confirmada por los narradores. Las explicaciones de los narradores modernos acerca de la muerte de la esposa a veces están un tanto alejadas de las concepciones católicas. Dios le envía una enfermedad con su mensajero el buitre cabecirroja o bien ella muere al momento de dar luz al fruto del adulterio - la idea de que el adulterio provoca un parto difícil es una concepción de origen prehispánico-. El éxito de la "muerte súbita" entre los nahuas quizás se explica si se entiende como la extensión, por así decirlo, de la conocida concepción nahua prehispánica de que la "falta" o transgresión puede ser causa de enfermedades (López Austin, 1980), la cual coincide en parte con la asociación católica entre pecado y enfermedad.

Varios exempla jesuitas presentan pecadores culpables de "lujuria", hombres y mujeres, adúlteros o "amancebados", castigados con enfermedad, muerte súbita y suplicios infernales (ex. 2-9). Sin embargo, en el relato moderno la falta es expresada más en términos de traición al concepto de pareja, base de se pretende fomentar el buen comportamiento de los esposos de acuerdo con la concepción de la pareja fiel y complementaria en las actividades cotidianas -otros relatos se ocupan de promover la fidelidad masculina-. Enfermedades, muerte y espíritus malos castigan a la mala pareja. De manera similar, en una de las versiones del relato nahua el pecado de la esposa parece corresponder a primera vista al antiguo pecado de "maldición": la esposa -que en esta versión no es culpable de adulteriova a la iglesia y pide a Dios la muerte de su esposo para poder casarse con otro. La maldición, es decir pedir a Dios o al diablo la muerte de una persona, aparece por lo menos en cinco exempla jesuitas (ex. 27-31) en los que el pecado es atribuido a los padres o al esposo. Este "pecado de palabra", ligado al de "ira", provoca en general la muerte de la persona maldita porque también ella es considerada culpable. Así, podemos citar los exempla del joven que golpea a su madre o del niño travieso, quienes mueren después de ser malditos por sus padres. Sin embargo, el caso

de la madre quien exasperada por su bebé llorón lo maldice, señala que la muerte del otro - aquí por supuesto inocente- castiga también al culpable de maldición. Así, estos exempla enseñan por una parte que los hijos deben obedecer y por otra que los padres deben refrenarse en maldecirlos. ${ }^{2}$ La versión aquí considerada del relato nahua moderno sigue más bien la idea general de que la muerte súbita castiga sólo al pecador: la esposa muere y el esposo inocente sobrevive. Quizá esto se explica por un cambio en la naturaleza del pecado de la esposa. En efecto, el hecho de ir a la iglesia en estado de ayuno para pedir a Dios o a los santos maldades hacia otras personas es considerado una hechicería. Para los narradores nahuas no se trata de una simple maldición, sino de un ritual de brujería, dirigido hacia una víctima inocente.

\section{LA VISIÓN DEL “INFIERNO” Y LOS CINCO SENTIDOS}

Después de la muerte de su esposa, el hombre sale llorando al monte y un buitre se ofrece a llevarlo a ver a su esposa. El esposo llega sobre las alas del ave al mundo de los muertos, donde es testigo de la forma en que vive ahí su esposa. Esta parte del relato muestra varios rasgos presentes en los exempla jesuitas: la estructura "pecado-muerte (súbita)-visión del castigo sobrenatural por un tercero"; una descripción vívida del "infierno", que involucra los cinco sentidos, por parte del testigo; la concepción del castigo como ligado a la naturaleza del pecado, y finalmente un episodio en el que el pecador dirige reproches hacia el visitante, considerado responsable del castigo. Si bien, veremos que la tradición oral nahua modificó de manera profunda los elementos heredados de la tradición de los exempla.

La estructura que hace posible la visión del castigo infernal por un testigo es una técnica convencional,

${ }^{2}$ No reviso aquí el caso único de la esposa maldita (ex. 31) porque es muy corto y no se especifica la razón por la cual el esposo se enoja. 
una "estrategia literaria" usada en los exempla jesuitas para lograr un mayor impacto y memorización de la enseñanza. Esta estructura permite incluir una vívida descripción de los tormentos y una interacción entre pecador y testigo, en la cual el primero explica la naturaleza de su pecado y la razón de su castigo (pp. 61, 109). No obstante, existe una diferencia importante entre el relato moderno y sus modelos jesuitas. En los exempla jesuitas traducidos al náhuatl esta visión siempre es una aparición o tiene lugar durante el sueño: el testigo no viaja al infierno; por el contrario, en el relato nahua moderno el hombre se traslada materialmente al mundo de los muertos y ve la escena con sus ojos físicos. Como el viaje es típico del relato de Orfeo en la América indígena, podemos pensar que allí se origina esta modalidad, pero este tema existe también en los exempla europeos. Un modelo en latín del exemplum 17 sobre usura -intitulado en la compilación Magnum speculum exemplorum - menciona que un ángel lleva al testigo de la mano "a una gran montaña de cuyo valle salen vapores" (p. 311), donde él puede oír y ver a sus parientes condenados. Queda por investigar más sobre este tema.

En cuanto a la presencia de los cinco sentidos, la visión es, como era de esperar, el sentido más importante. En el relato moderno el buitre previene al hombre: "observarás algo especial/sorprendente", tonmauisos. Este término se relaciona con la palabra tlamauiçolli, usada por el franciscano Olmos para designar un ejemplo, en el sentido de "prodigio" (p. 67). El esposo -y el auditor a través de sus ojos- observa al llegar el panorama de este mundo, con sus casas e iglesia. Busca con la mirada a su esposa entre las numerosas almas. Ella lo invita entonces a su casa, en algunas versiones lo esconde en una jarra o dentro de un petate enrollado y deja un pequeño espacio o agujero para que él pueda ver sin ser visto por el diablo, que se presentará, la castigará y se irá. Una de las versiones menciona las fuertes reacciones emocionales del esposo frente a esta visión, lo que le otorga más impacto aun como imagen mental para quien atiende el relato.
En cuanto al sentido del oído, el esposo debe escuchar los reproches de su esposa, como veremos después, y todo un intercambio verbal convencional entre ella y el diablo - saludos, invitación a comer, etc.-. Por su parte, éste introduce los sentidos del olfato y del gusto. Al entrar, de inmediato se pone a oler por todos lados y pregunta a la mujer qué es ese buen olor a melón que invade la casa. La mujer le contesta que no hay nada, pues ella bien sabe que el diablo detecta el buen aroma de carne viva que despide su esposo y querrá comerlo. Finalmente, el sentido del tacto entra en juego cuando el hombre intenta tomar a su esposa de la mano, tener relaciones sexuales con ella o pegarle, en algunas versiones, y se da cuenta de que no puede hacerlo porque ella es ahora un fantasma, un cuerpo sin consistencia. Todos estos elementos sensuales permiten una potente visión del mundo de los muertos a través de los sentidos y emociones del héroe. Cabe recordar que el uso de imágenes fuertes también es típico del cuento europeo (Belmont, 1999). Podemos pensar en la muchacha que descubre el cuarto ensangrentado donde Barba Azul conserva el cuerpo de sus esposas asesinadas. Los cuentos de origen europeo fueron otra de las influencias primordiales en los relatos tradicionales nahuas de hoy: las técnicas de los dos géneros -el cuento y el relato de pecadosprobablemente se fusionaron perfectamente en esta visión del "infierno".

\section{LA CORRESPONDENCIA PECADO-CASTIGO Y LOS REPROCHES DEL “CONDENADO”}

El momento más impactante de la visión es probablemente cuando el esposo escondido atestigua el castigo de su esposa adúltera, según el modelo de los exempla coloniales. No todas las versiones del relato mencionan un castigo, pero cuando lo hacen éste es el abuso sexual de la pecadora por un diablo o varios que entran a su casa. En la concepción cristiana vinculada con los exempla jesuitas el castigo es ligado a la naturaleza del pecado en un sistema de 
inversión: el dolor sustituye al placer. Así, el glotón tendrá que comer sus propios miembros cocidos $\mathrm{y}$ asados, y el borracho tomar una bebida de azufre (p. 118). Los pecados sexuales, sin embargo, son castigados de manera más metafórica, en el sentido de que el suplicio no involucra relaciones sexuales: por ejemplo, los pecadores verán morder su sexo por serpientes monstruosas, la mujer lujuriosa tendrá que montar un dragón con la piel ardiente (p. 119). El relato nahua sigue la misma lógica de inversión, pero deja de lado la metáfora y la mujer es castigada de la misma forma en la que gozó: por relaciones sexuales. Esto se debe en parte a la idea de que el mundo de los muertos es un espejo, una prolongación del mundo de los vivos. Las actividades que uno tiene en la tierra continúan en Chiknaujtipan y a medida en que mueren los miembros de la familia ésta se reconstruye allá. Esta característica del mundo de los muertos, entre otras que no podemos revisar aquí, permite comprender por qué en algunas versiones la mujer no es castigada. Veamos otro los reproches del pecador.

Como hemos advertido, algunos pecadores de los relatos jesuitas maldicen a miembros de su familia. De manera general, blasfemias y maldiciones "representan el signo convencional con el que se reconoce a los condenados en los exempla" (p. 105). En efecto, escuchar continuamente estas imprecaciones hace parte de los suplicios del infierno. En algunos exempla traducidos al náhuatl el condenado lanza reproches o maldice directamente a otras personas responsables de su comportamiento. Tomaré el caso de la pequeña obra de teatro titulada "La mala educación” (pp. 345-351 y ex. 45 del Anexo). Un hijo borracho y mujeriego mata a sus padres y es llevado al infierno. Allí encuentra a su padre también condenado y le reprocha: “ $i A y$, ay, ay! ¡Eres mi padre diabólico! ¿Acaso desde hace poco has reflexionado? ¡Si me hubieras gritado, quizás no hubiera hecho eso! Ahora estaremos reunidos en el sufrimiento y nos daremos de bofetadas". El joven condenado continúa con sus reproches: “Terminé por completo mi vida

terrestre por culpa del pecado de mi padre. ¡Me crió en el amor!" (pp. 329-330 y 341-342 del Anexo). En una de las versiones del relato nahua moderno, la mujer castigada por los diablos increpa al esposo con reproches similares, aun en el uso de términos insultantes: “¡Pendejo! Si me hubieras castigado en la tierra, aun con sólo un cachete, no estaría sufriendo así ahora! ¡Me amabas mucho!”. El esposo, sumamente enojado por haber visto a su mujer tener relaciones sexuales con los diablos — prueba de que fue adúltera- $\mathrm{y}$ animado por sus reproches, quiere golpearla pero no lo logra porque no puede tocarla. En otra versión, la esposa le reclama a su esposo haberla dejado sola — vulnerable entonces a la tentación del adulterio y a los chismes - y le anuncia que a su muerte vendrá a reemplazarla y ella irá a otro lugar más agradable. Los reproches son muy distintos en estas dos versiones modernas, pero comparten una idea presente en varios exempla jesuitas y en el pensamiento nahua: que el pecado o falta puede ser el resultado del comportamiento deficiente de varias personas, porque unas son responsables de la conducta de otras, según el sistema jerárquico padres-hijos, esposo-esposa.

En otras versiones del relato la mujer no es castigada, simplemente vive en el mundo de los muertos como vivió en la tierra y tiene relaciones sexuales con hombres. Según las explicaciones de un narrador, los diablos no viven en Chiknaujtipan —son más bien habitantes de las cuevas-, que no es propiamente un infierno, sólo vienen a castigar las almas de los que fueron pecadores. En una de las versiones en la que la mujer no es castigada se presentan reproches. Se trata de la mujer que pidió a Dios la muerte de su esposo ausente para poder casarse con otro. Frente a su marido, que fue a verla al mundo de los muertos, ella tiene relaciones con dos almas de hombres que la esperan en casa - no esconde a su esposo porque estas almas humanas son inofensivas en el relato-. Después de haber gozado con ellos, mira a su esposo terrestre y le dice: "Ves, así quería yo que viviéramos juntos, pero tú no quisiste. ¡Ahora vete!”. En este caso, los reproches de los 
exempla tendrían un sentido desviado: ¡comportarse bien significa satisfacer a su esposa en la tierra! Debemos recordar que en tiempos prehispánicos se advertía a los jóvenes que su esposa buscaría un amante de no poder satisfacerla, no por ausencia en este caso, sino por agotamiento de las fuerzas viriles en una sexualidad demasiado temprana, antes del matrimonio (López Austin, 1980).

\section{CONSIDERACIONES FINALES}

Con el caso del viaje al mundo de los muertos constatamos que los exempla dejaron huellas importantes en la tradición oral nahua. Algunas fueron favorecidas por ciertas concordancias entre las concepciones prehispánicas y católicas que los misioneros no dudaron en usar en su evangelización, con lo que crearon una serie de malentendidos culturales. Estas huellas pueden identificarse ahora con una precisión más aguda gracias al detallado y fino análisis de Dehouve. En la tradición oral, como lo menciona la autora, la lógica ya no es eclesiástica sino pueblerina: el "ejemplo" moderno pretende controlar primeramente no la fe del auditor, sino su comportamiento en el conjunto de reglas sociales y cosmológicas que rigen la vida de la comunidad - como la fidelidad de la pareja-. Así, podemos ver que la concepción de los pecados ha sufrido cambios relevantes. El tema de la lujuria se trastoca en traición a la pareja por el adulterio femenino y por el abandono - aun temporal- masculino. Por su parte, la maldición se convierte en brujería. La visión y los castigos se alejan de la simbolización cristiana, ya que el hombre se encuentra físicamente entre las almas y la mujer es castigada - o recompensadacon verdaderas relaciones sexuales.
Sobre todo, las imágenes, los acontecimientos y la moraleja son más variados, ya que la tradición oral no respeta el estereotipo jesuita del "pecador universal". En este sentido, el éxito de los jesuitas en su enseñanza fue limitado, a pesar de sus logros en la deconstrucción del universo mental nahua o en la imposición de creencias, como el castigo por "muerte súbita" o los reproches del condenado. Roland Barthes (citado en p. 61 de la obra) menciona cómo la imagen ignaciana "se sitúa en los antípodas de lo imaginario. Para iniciar la formación de una imagen y abstraerse en su contemplación, es necesario impedir la intrusión de otras imágenes espontáneas". Al igual que los casos del capítulo 11 de la imprescindible obra de Danièle Dehouve, el relato nahua en sus diversas versiones muestra que la tradición oral conservó la fuerza y el impacto de la imagen "sensual" y otros elementos de los exempla, pero se liberó de la camisa de fuerza jesuita para permitir la introducción del imaginario y de las concepciones indígenas.

\section{BIBLIOGRAFÍA}

Belmont, Nicole, 1999, Poétique du conte. Essai sur le conte de tradition orale, Gallimard, París.

Dehouve, Danièle, 2010, Relatos de pecados en la evangelización de los indios de México (siglos XVI-XVIII), Centro de Investigaciones y Estudios Superiores en Antropología Social, Centro de Estudios Mexicanos y Centroamericanos, México.

López Austin, Alfredo, 1980, Cuerpo humano e ideología. Las concepciones de los antiguos nahuas, Universidad Nacional Autónoma de México, México.

Soustelle, Jacques, 1959, Pensamiento cosmológico de los antiguos mexicanos. Representación del mundo y del espacio, Federación Estudiantil Poblana, Puebla.

Raby, Dominique, 2003, L'épreuve fleurie. Symboliques $d u$ genre dans la littérature nahuatl du Mexique préhispanique, L'Harmattan, París. 